\title{
Case report of de novo dup(18p)/del(18q) and $r(18)$ mosaicism
}

\author{
Enkhtuvshin Gereltzul $\cdot$ Yoshiyuki Baba $\cdot$ Naoto Suda $\cdot$ Momotoshi Shiga \\ Maristela Sayuri Inoue · Michiko Tsuji · Insik Shin · Yukio Hirata • \\ Kimie Ohyama $\cdot$ Keiji Moriyama
}

Received: 29 March 2007/ Accepted: 8 July 2008/Published online: 5 August 2008

(C) The Japan Society of Human Genetics and Springer 2008

\begin{abstract}
This is a report of a 27-year-old woman with an unusual de novo chromosomal abnormality. Mosaicism was identified in peripheral blood cells examined by standard G-bands by trypsin using Giemsa (GTG) analysis and fluorescence in situ hybridization (FISH) analysis with chromosome-18 region-specific probes, 46, XX, del(18)(pter $\rightarrow$ q21.33:)[41], 46,XX,r(18)(::p11.21 $\rightarrow$ q21.33::)[8], and 46,XX,der(18)(pter $\rightarrow$ q21.33::p11.21 $\rightarrow$ pter)[1]. On the other hand, the karyotype of periodontal ligament fibroblasts was nonmosaic, 46,XX, $\operatorname{der}(18)$ (pter $\rightarrow$ q21.33::p11.21 $\rightarrow$ pter)[50]. All cell lines appeared to be missing a portion of $18 \mathrm{q}(\mathrm{q} 21.33 \rightarrow$ qter). The pattern of the $\operatorname{dup}(18 \mathrm{p}) / \operatorname{del}(18 \mathrm{q})$ in the rod configuration raises the possibility of an inversion in chromosome 18 in one of the parents. However, no chromosomal anomaly was detected in either parent. The most probable explanation is that de novo rod and ring configurations arose simultaneously from an intrachromosomal exchange. The unique phenotype of this patient, which included primary hypothyroidism and primary hypogonadism, is discussed in relation to her karyotype.
\end{abstract}

E. Gereltzul · Y. Baba $(\varangle) \cdot$ N. Suda $\cdot$ M. Shiga ·

M. S. Inoue · M. Tsuji - I. Shin · K. Ohyama - K. Moriyama

Maxillofacial Orthognathics, Graduate School,

Tokyo Medical and Dental University, 1-5-45,

Yushima, Bunkyo-Ku, Tokyo 113-8549, Japan

e-mail: y-baba.mort@tmd.ac.jp

\section{Y. Hirata}

Clinical and Molecular Endocrinology,

Graduate School, Tokyo Medical and Dental University,

Tokyo, Japan
Keywords Deletion 18q · Ring chromosome 18 . Rod/ring mosaicism · Hypothyroidism · Hypogonadism

\section{Introduction}

Deletion of the long arm of chromosome 18 [del(18q)] occurs in about 25 of every one million newborns. $\operatorname{Del}(18 \mathrm{q})$ syndrome is characterized by short stature, microcephaly, disturbed brain myelinization, mental deficiency, hypotonia, midface hypoplasia, prominent anthelix, hearing impairment, tapered fingers, and genital abnormalities, particularly in males (Wertelecki and Gerald 1971; Gorlin et al. 1990; Schinzel et al. 1991; Gay et al. 1997; Cody et al. 1999; Linnankivi et al. 2003). Congenital heart defects may also be found (Gorlin et al. 1990; Sturm et al. 2000). A variety of other features have been recorded, including cleft palate, eye abnormalities, downturned corners of the mouth, low-set ears and a low hair line (Gorlin et al. 1990; Cody et al. 1997; Gustavsson et al. 1999; Zannolli et al. 2003).

Several studies have reported growth hormone deficiency in patients with del(18q) (Cody et al. 1997; Ghidoni et al. 1997; Hale et al. 2000). Ghidoni et al. (1997) suggested that a gene or genes on the long arm of chromosome 18 may be involved in growth hormone production. Hypothyroidism and hypogonadism occur less commonly. Pernicious anemia, ectodermal dysplasia, harlequin ichthyosis, autoimmune thyroiditis, and insulin-dependent diabetes mellitus also have been reported, albeit rarely (Dacou-Voutetakis et al. 1999; Gustavsson et al. 1999; Stewart et al. 2001; Zannolli et al. 2003). Immunoglobulin A (IgA) deficiency has been recorded in several instances (Hecht 1969). The clinical spectrum varies greatly depending on the extent of the deletion. Terminal deletions 
of the long arm of chromosome 18 are most common, and in some cases, the deletion occurs from one or both arms of chromosome 18, and the chromosomal ends join to form a ring (Stankiewicz et al. 2001). Most patients with $\mathrm{r}(18)$ are female, usually have a less severe phenotype than found with del(18q) (Miller et al. 2003), and may be associated with a short neck without cardiac anomalies (Stankiewicz et al. 2001). Patients may sometimes show mosaicism with more than one chromosomal anomaly, such as the combination of $\operatorname{del}(18 \mathrm{q})$ and $\mathrm{r}(18)$.

On the other hand, rod/ring mosaicism, in which the rod and ring configurations arise simultaneously, has been reported in chromosome 2 (Wyandt et al. 1982). We describe herein an unusual case of de novo rod/ring mosaicism, dup(18p)/del(18q), and $\mathrm{r}(18)$, with primary hypothyroidism and primary hypogonadism.

\section{Case report}

The patient was a 27-year-old Japanese woman with a chief complaint of malocclusion and articulation problems. The patient was the first child of nonconsanguineous, healthy parents. At the time of her birth, her mother and father were both 25 years old. The patient was born at 41 weeks gestation with a birth weight of 2,555 g and length of $48 \mathrm{~cm}$. She was found to have a cleft lip and palate. No chromosomal anomaly was detected in either her parents or brother. The medical history of this patient included lip closure at 6 months, hard-palate closure at 1 year 6 months, fistula closure at 2 years 9 months, surgery for foot deformity at 3 years, pharyngeal flap surgery at 7 years, and secondary bone grafting for cleft site at 23 years. From age 6-17 years, the patient had speech therapy. Since age 17, she has received hormone replacement therapy (1-thyroxine and estrogens) for primary hypothyroidism due to Hashimoto thyroiditis and amenorrhea due to primary hypogonadism, respectively. We obtained permission from the patient and her parents for publication.

\section{General examination}

The phenotype of this patient was mostly consistent with del(18q) syndrome, including mental retardation, short stature, and hypotonia. An examination revealed several skeletal abnormalities. She had short, thin, and tapered fingers, proximally placed thumbs, clinodactyly, feet deformity (Fig. 1), vertebral fusion (C2-C3) (Fig. 2a, b), short neck, and enlarged elbow joints. Ectodermal dysplasia of the skin, hair, and nails was also observed. The patient was found to have decreased secondary sexual characteristics, including undeveloped breasts and sparse axillary and pubic hair. No goiter was noted.

\section{Craniofacial appearance}

Microcephaly, oxycephaly, and midfacial hypoplasia were noted, as shown in Fig. 2a, b. Downturned corners of the mouth, deeply set eyes, lateral displacement of the inner canti, upslanting palpebral fissures, and prominent anthelix were also noted (Fig. 2c-e). In addition, narrow airway, tonsillitis, otitis media with mild hearing loss on the left side, and postoperative unilateral cleft lip and palate were also found (Fig. 2c, f, g).

\section{Oral manifestations}

Negative overjet and excessive overbite with large freeway space, caused by midfacial deficiency, were observed. Congenital absence of the maxillary lateral incisors and
Fig. 1 Abnormalities of the hand and foot. The proximally placed thumbs, clinodactyly, short and tapered fingers $(\mathbf{a}, \mathbf{b})$, and feet deformity (c). Handwrist radiographs of both hands and feet $(\mathbf{d}, \mathbf{e})$
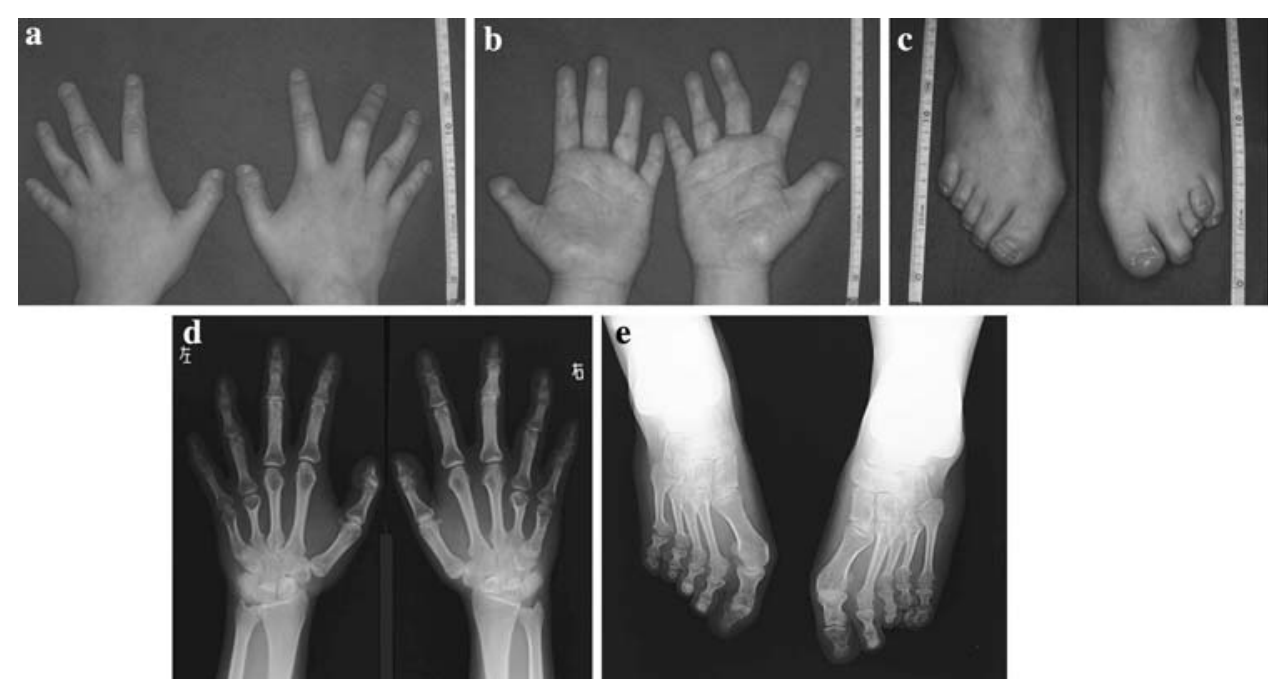

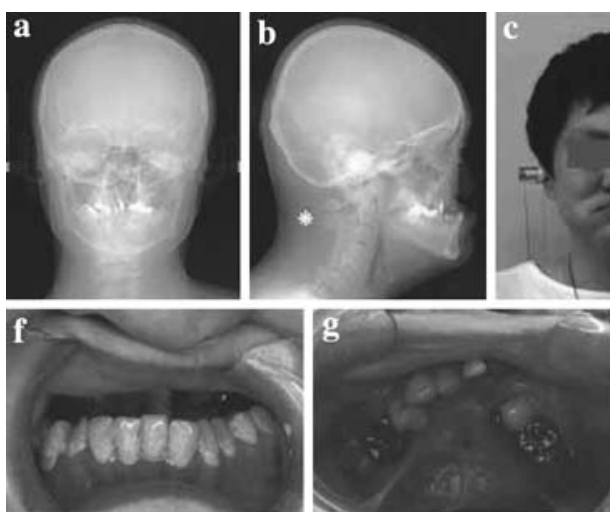

Fig. 2 Craniofacial appearance and oral manifestations. Cephalometric radiographs show microcephaly and oxycephaly, midfacial dysplasia, and vertebral fusion of $\mathrm{C} 2-\mathrm{C} 3$ (asterisk) (a, b). The midfacial hypoplasia, downturned corners of the mouth (c), deeply set eyes, lateral displacement of the inner canti, upslanting palpebral

second premolars on both sides, impaction of the maxillary left canine, and macroglossia were also seen (Fig. 2f-i).

Chromosomal findings

Chromosome analysis was performed on peripheral blood lymphocyte cultures and fibroblasts derived from periodontal ligament tissue of an extracted wisdom tooth. Standard G-bands by trypsin using Giemsa (GTG) analysis revealed 46,XX,del(18)(pter $\rightarrow$ q21.33:)[41], 46,XX,r(18) $(:: p 11.21 \rightarrow$ q21.33::)[8], and 46,XX,der(18)(pter $\rightarrow$ q21. 33::p11.21 $\rightarrow$ pter)[1] in blood lymphocyte cells (Fig. 3ac) and 46,XX, der(18)(pter $\rightarrow$ q21.33::p11.21 $\rightarrow$ pter)[50] in periodontal ligament fibroblasts (Fig. 3d). All cell lines appeared to be missing a portion of $18 \mathrm{q}(\mathrm{q} 21.33 \rightarrow$ qter).

Fluorescence in situ hybridization (FISH) analysis for chromosome 18 (Fig. 3e-j; blood lymphocyte cells, k, 1; periodontal ligament cells) was carried out using centromere- and subtelomere-specific probes. The $18 p$ and $18 \mathrm{q}$ subtelomere-specific probes employed were Mixture 11 and Mixture 12 of ToTelVysion (Abbott Molecular Inc., USA.), respectively. Fifty metaphases of peripheral blood cells using $18 \mathrm{p}$ subtelomere-specific probes revealed ish 46,XX,18(18pterx1,D18Z1x1),del(18)(18pter-,D18Z1+) [41]/46,XX,18(18pterx1,D18Z1x1),r(18)(D18Z1+,18qter -)[8]/46,XX,18(18pterx1,D18Z1x1),der(18)(18pter++, D18Z1+)[1] (Fig. 3e-g). In 50 more blood lymphocyte cells, FISH using 18q subtelomere-specific probe, showed ish 46,XX,18(D18Z1x1,18qterx1),del(18)(D18Z1+,18qter -)[44]/46,XX,18(D18Z1x1,18qterx1),r(18)(D18Z1+,18qter -)[5]/45,XX,18(D18Z1x1,18qterx1)[1] (Fig. 3h-j). On the other hand, analysis of periodontal ligament cells using $18 \mathrm{p}$ and $18 \mathrm{q}$ subtelomere-specific probes in each 50 cells showed nonmosaicism, ish 46,XX,18(18pterx1,D18Z1x1,18qterx1), der(18)(18pter++,D18Z1+,18qter-) (Fig. 3k, 1). fissures (d), prominent anthelix (asterisk) (e), negative overjet and excessive overbite with a large freeway space, intermaxillary discrepancy with severe crossbite (f), left cleft lip and palate (c, f, g), and macroglossia (h). The multiple congenital missing teeth in the maxilla and impaction of the left canine in a panoramic radiograph (i)

\section{Discussion}

A 27-year-old woman with de novo rod/ring mosaicism, $\operatorname{dup}(18 \mathrm{p}) / \mathrm{del}(18 \mathrm{q})$ and $\mathrm{r}(18)$, in peripheral blood cells is reported. De Pater et al. (2003) suggested that chromosome 18 might carry a high number of certain sequences, which are susceptible to interchromosomal as well as intrachromosomal rearrangements. The most frequent of these abnormalities are deletions and ring chromosome formation. Rings often appear as mosaics, as a consequence of the structural instability of the ring during cell division (Baumer et al. 2002; Miller et al. 2003). There have been reports of cases with chromosome 18 mosaicism, mostly involving chromosome 18 in different cell lines, including $\mathrm{r}(18)$, der(18), r(18)x2, monosomy 18 (Stankiewicz et al. 2001; De Pater et al. 2003; Miller et al. 2003; Carreira et al. 2007). Overall, these patients with $r(18)$ often share clinical features with del(18q) syndrome, del(18p) syndrome, or their combination, depending on the size of the deletion. The incidence and type of congenital malformations in cases of $\mathrm{r}(18)$ are similar to those in patients carrying del(18)(q21-qter) (Schinzel 2001).

The exact mechanism of the mosaicism in our case is not known. The pattern of the $\operatorname{dup}(18 \mathrm{p}) / \mathrm{del}(18 \mathrm{q})$ seen in both peripheral blood cells and fibroblasts in the rod configuration raises the possibility of an inversion in chromosome 18 in one of the parents. However, no chromosomal anomaly was detected in either parent. Furthermore, the finding of an inversion would not explain the finding that the ring chromosome lacked the chromosomal material, p11.21 $\rightarrow$ pter, which is duplicated in the rod. Wyandt et al. (1982) reported rod/ring mosaicism of chromosome 2, and the most probable explanation is that the rod and ring configurations arose simultaneously from an intrachromosomal exchange. An isochromatid break in 
a
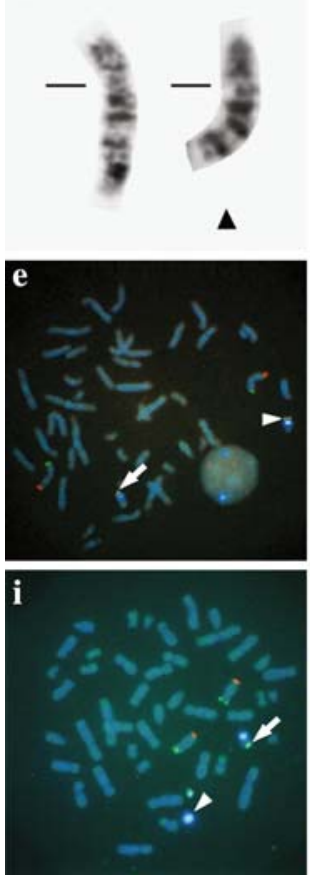

b
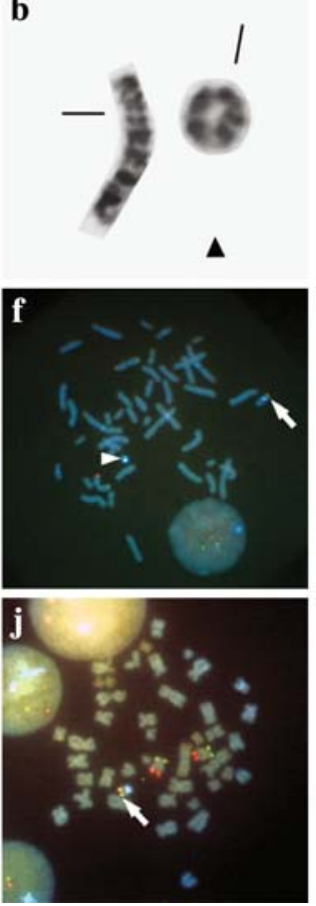

Fig. 3 Chromosomal analysis. Karyotypes of the patient by the G-banding method revealed 46,XX,del(18)(pter $\rightarrow$ q21.33:)[41], 46,XX,r(18)(::p11.21 $\rightarrow$ q21.33::)[8], and 46,XX,der(18)(pter $\rightarrow$ q21.33::p11.21 $\rightarrow$ pter)[1] in blood lymphocyte cells (a, b and c, respectively). Periodontal ligament fibroblasts (d) revealed 46,XX, $\operatorname{der}(18)($ pter $\rightarrow$ q21.33::p11.21 $\rightarrow$ pter)[50]. Bars indicate centromere positions (a-c), and arrowheads abberant chromosomes (18) (a-d). Fluorescent in situ hybridization (FISH) analysis for chromosome 18 (e-j; blood lymphocyte cells, $\mathbf{k}, \mathbf{l}$; periodontal ligament cells) using centromere- and subtelomere-specific probes. The results with blood cells were: 46,XX,18(18pterx1,D18Z1x1),del(18)(18pter+,D18Z1+) (e); 46,XX,18(18pterx1,D18Z1x1),r(18)(18pter-,D18Z1+) (f); 46, XX,18(18pterx1,D18Z1x1),der(18)(18pter++,D18Z1+) (g); 46,XX,

the long arm and a single chromatid break in the short arm of chromosome 18 were followed by rejoining of the broken ends to give dup(18p)/del(18q) and r(18) (Fig. 4). As a result, the chromosomal material, p11.21 $\rightarrow$ pter, was duplicated and deleted in the rod and ring configurations, respectively. On the other hand, the fragment q21.33 $\rightarrow$ qter was deleted from the long arm. Subsequent cell division would give rise to daughter cells representing the two cell lines in the patient. Differential selection against cells with the ring chromosome in blood and oral tissue probably occurred during subsequent embryological development. On the other hand, deletion of $18(\mathrm{p} 11.21 \rightarrow$ pter $)$ from the rod configuration, $\operatorname{dup}(18 \mathrm{p}) / \operatorname{del}(18 \mathrm{q})$, is speculated to be secondary, which deliver "del(18q)" (Fig. 3a) in peripheral blood cells. Additional cell lines have also been reported in lymphocyte cultures when compared with fibroblasts (Wyandt et al. 1982; Zahed et al. 2004). Modi et al. (2003) also reported mosaicism in peripheral blood but not in other tissues (buccal cells or amniocytes). One of 50 blood

c
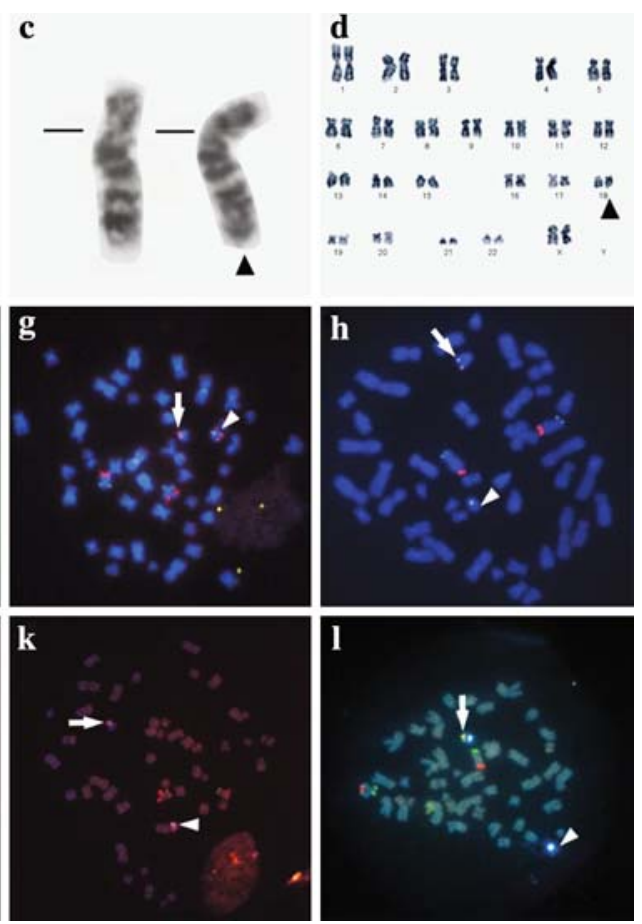

18(D18Z1x1,18qterx1), del(18)(D18Z1+,18qter-) (h); 46,XX,18 (D18Z1x1,18qterx1),r(18)(D18Z1+,18qter-) (i); 45,XX,18(D18Z1x1, 18qterx1) (j). FISH analysis of periodontal ligament cells revealed ish 46,XX,18(18pterx1,D18Z1x1),der(18)(18pter++,D18Z1+)[50] for $18 \mathrm{p}$ subtelomere (k) and ish 46,XX,18(D18Z1x1,18qterx1),$\operatorname{der}(18)(\mathrm{D} 18 \mathrm{Z1}+, 18 \mathrm{qter}-)$ [50] for 18q subtelomere (l). Arrows indicate intact chromosomes 18 and arrowheads aberrant chromosomes $18.18 \mathrm{p}(\mathbf{e}-\mathbf{g}, \mathbf{k})$ and $18 \mathrm{q}(\mathbf{h}-\mathbf{j}, \mathbf{l})$ subtelomere-specific probes employed were Mixture 11 and Mixture 12 of ToTelVysion (Abbott Molecular Inc., USA), respectively, as indicated by yellow signals, and 18 cen by blue signals. Signals for chromosomes $11(\mathbf{e}-\mathbf{g}, \mathbf{k})$ and $12(\mathbf{h}-\mathbf{j}$, l) were used as controls (green short-arm subtelomere, red long-arm subtelomere)

cells in our case showed $45, \mathrm{XX},-18$. This cell line might have started as an $\mathrm{r}(18)$, and mitotic instability and crossing-over events between the ring sister chromatids led to its loss during cell division, which generated the monosomy. However, monosomy 18 might be considered as a culture artifact (Fischer et al. 2001; Schinzel 2001).

To determine the critical region for the $\operatorname{del}(18 \mathrm{q})$ syndrome, a genotype-phenotype correlation has been studied (Kline et al. 1993; Brkanac et al. 1998; Cody et al. 1999). Zannolli et al. (2003) described a patient with $\operatorname{del}(18)$ (q21.31-qter) who had ectodermal dysplasia syndrome with a wide spectrum of abnormalities and a family pedigree with normal karyotypes, suggesting its subtle involvement in the development of ectodermal and/or mesodermal structures. Stewart et al. (2001) described another case of del(18)(q21.3) syndrome associated with harlequin ichthyosis, an autosomal recessive skin disorder, and speculated that the responsible gene may lie at or distal to 18q21.3. In a review of this syndrome, Schinzel (2001) 


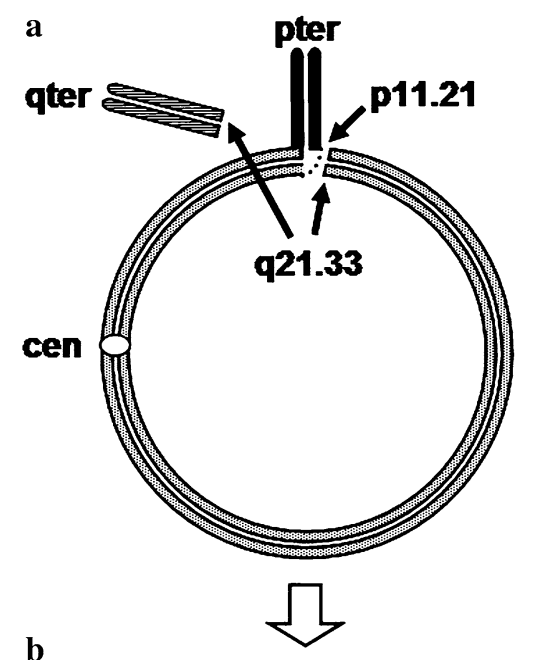

b

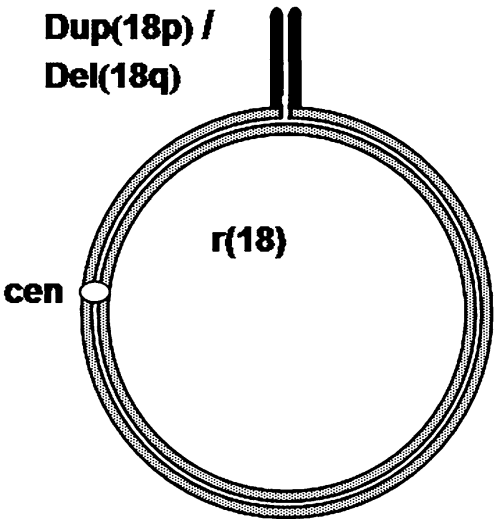

Fig. 4 Proposed mechanism of the rod/ring configuration. Intrachromosomal exchange involving an isochromatid break in the long arm and a single chromatid break in the short arm of chromosome 18 . The solid shaded segment, p11.21 $\rightarrow$ pter, was duplicated and deleted in the rod and ring configurations. The striped fragment, q21.33 $\rightarrow$ qter, was deleted (a). Configuration after rejoining at the break points showing $\operatorname{dup}(18 \mathrm{p}) / \operatorname{del}(18 \mathrm{q})$ and $\mathrm{r}(18)$ (b). cen, centromere

described the presence of several less-common defects, such as brachycephaly, midface hypoplasia, coxa valga, and sparse hair. Zannolli et al. (2003) suggested that complex mechanisms may be involved in diversification of the neural crest, endoskeletal elements, brain organization, and the organization of other body parts, such as bones and teeth. The patient in our study also had several congenital abnormalities, including missing teeth; canine impaction; skin, hair, and nail dysplasia; vertebral fusion; and other skeletal and osteoarticular abnormalities. The association of a short neck in the absence of congenital heart defects may suggest the deletion of $18 \mathrm{p}$ material on ring chromosome 18 (Stankiewicz et al. 2001). However, such unique features might be explained by subtle involvement in the development of mesodermal structures. On the other hand, IgA deficiency, a common feature of chromosome 18p anomaly (Israels et al. 1996), has been reported in some cases of del(18q) (Hecht 1969) and ring chromosome (Burgio et al. 1980) but was not observed in this case.

Our patient had primary hypothyroidism due to Hashimoto thyroiditis and primary hypogonadism. Endocrine disorders have been reported, although rarely, in patients with del(18q) syndrome with similar breakpoints; a 4-yearold boy with type I diabetes and autoimmune thyroiditis who had a ring chromosome 18 (deletion 18q22.3-18qter) (Dacou-Voutetakis et al. 1999), and a 13-year-old girl with primary hypothyroidism who had a deletion of the long arm of chromosome 18 [del(18)(q21.3)] (Henrot et al. 1989). Therefore, it is possible to speculate that some gene(s) located on chromosome 18 are responsible for the polyglandular autoimmune process. Growth hormone deficiency and secondary hypogonadism in a boy with a ring 18 chromosome has been reported previously (Abusrewil et al. 1988). However, it was not the case in our study, where the patient had primary hypogonadism. Zahed et al. (2004) reported another case of an adult male with ring chromosome 18q and jumping translocation 18p who had partial primary hypogonadism as the sole phenotypic abnormality. The primary hypogonadism in our patient, a unique feature that has not been previously associated with $\mathrm{r}(18)$ of different sizes (Stankiewicz et al. 2001; Yardin et al. 2001; Baumer et al. 2002), may raise the possibility that deletion of the long arm of chromosome 18 may be responsible for the development of primary gonadal and thyroid failure. Such clinical traits in our case seem to be consistent with deletion in the long arm of chromosome 18.

This case shows an unusual cytogenic lesion; i.e., de novo rod and ring mosaicism. Further studies are needed to delineate the responsible critical regions and the genotypephenotype relation in del(18q) syndrome.

\section{References}

Abusrewil SS, McDermott A, Savage DC (1988) Growth hormone, suspected gonadotrophin deficiency, and ring 18 chromosome. Arch Dis Child 63:1090-1091

Baumer A, Giovanucci Uzielli ML, Guarducci S, Lapi E, Rothlisberger B, Schinzel A (2002) Meiotic origin of two ring chromosome 18 in a girl with developmental delay. Am J Med Genet 113:101-104

Brkanac Z, Cody JD, Leach RJ, DuPont BR (1998) Identification of cryptic rearrangements in patients with $18 \mathrm{q}$-deletion syndrome. Am J Hum Genet 62:1500-1506

Burgio GR, Duse M, Monafo V, Ascione A, Nespoli L (1980) Selective IgA deficiency: clinical and immunological evaluation of 50 pediatric patients. Eur J Pediatr 133:101-106

Carreira IM, Mascarenhas A, Matoso E, Couceiro AB, Ramos L, Dufke A, Mazauric M, Stressig R, Kosyakova N, Melo JB, Liehr $\mathrm{T}$ (2007) Three unusual but cytogenetically similar cases with up to five different cell lines involving structural and numerical abnormalities of chromosome 18. J Histochem Cytochem $55: 1123-1128$ 
Cody JD, Pierce JF, Brkanac Z, Plaetke R, Ghidoni PD, Kaye CI, Leach RJ (1997) Preferential loss of the paternal alleles in the 18q-syndrome. Am J Med Genet 69:280-286

Cody JD, Ghidoni PD, DuPont BR, Hale DE, Hilsenbeck SG, Stratton RF, Hoffman DS, Muller S, Schaub RL, Leach RJ, Kaye CI (1999) Congenital anomalies and anthropometry of 42 individuals with deletions of chromosome 18q. Am J Med Genet $85: 455-462$

Dacou-Voutetakis C, Sertedaki A, Maniatis-Christidis M, Sarri C, Karadima G, Petersen MB, Xaidara A, Kanariou M, Nicolaidou $P$ (1999) Insulin dependent diabetes mellitus (IDDM) and autoimmune thyroiditis in a boy with a ring chromosome 18: additional evidence of autoimmunity or IDDM gene(s) on chromosome 18. Am J Med Genet 36:156-158

De Pater JM, Smeets DFCM, Scheres JMJC (2003) Unique mosaicism of structural chromosomal rearrangement: is chromosome 18 preferentially involved? Am J Med Genet A 119:26-31

Fischer W, Dermitzel A, Osmers R, Pruggmayer M (2001) Complete karyotype discrepancy between placental and fetal cells in a case of ring chromosome 18. Prenat Diagn 21:481-483

Gay CT, Hardies LJ, Rauch RA, Lancaster JL, Plaetke R, DuPont BR, Cody JD, Cornell JE, Herndon RC, Ghidoni PD, Schiff JM, Kaye CI, Leach RJ, Fox PT (1997) Magnetic resonance imaging demonstrates incomplete myelination in 18q-syndrome: evidence for myelin basic protein haploinsufficiency. Am J Med Genet 74:422-431

Ghidoni PD, Hale DE, Cody JD, Gay CT, Thompson NM, McClure EB, Danney MM, Leach RJ, Kaye CI (1997) Growth hormone deficiency associated in the $18 \mathrm{q}$ deletion syndrome. Am J Med Genet 69:7-12

Gorlin RJ, Cohen MM, Levin LS (1990) Chromosomal syndromes: common and well-known syndromes. In: Syndromes of the head and neck, 3rd edn, Oxford University Press, New York, pp 53-54

Gustavsson P, Kimber E, Wahlström J, Annerén G (1999) Monosomy $18 \mathrm{q}$ syndrome and atypical Rett syndrome in a girl with an interstitial deletion (18)(q21.1q22.3). Am J Med Genet 82:348-351

Hale DE, Cody JD, Baillargeon J, Schaub R, Danney MM, Leach RJ (2000) The spectrum of growth abnormalities in children with 18q deletions. J Clin Endocrinol Metab 85:4450-4454

Hecht F (1969) IgA and partial deletions of chromosome 18. Lancet $1: 100-101$

Henrot B, Ninane J, Mercenier C, Vermylen C, Verellen C, Cornu G, Malvaux P (1989) Deletion of the long arm of chromosome 18, primary hypothyroidism, Biermer's anemia and IgM hypogammaglobulinemia. Arch Fr Pediatr 46:729-732

Israels T, Hoovers J, Turpijn HM, Wijburg FA, Hennekam RC (1996) Partial deletion of $18 \mathrm{p}$ and partial duplication of $18 \mathrm{q}$ caused by a paternal pericentric inversion. Clin Genet 50:520-524

Kline AD, White ME, Wapner R, Rojas K, Biesecker LG, Kamholz J, Zackai EH (1993) Molecular analysis of the 18q- syndrome - and correlation with phenotype. Am J Hum Genet 52:895-906
Linnankivi TT, Autti TH, Pihko SH, Somer MS, Tienari PJ, Wirtavuori KO, Valanne LK (2003) 18q-syndrome: brain MRI shows poor differentiation of gray and white matter on T2weghted images. J Magn Reson Imaging 18:414-419

Miller K, Pabst B, Ritter H, Nürnberg P, Siebert R, Schmidtke J, Arslan-Kirchner M (2003) Chromosome 18 replaced by two ring chromosomes of chromosome 18 origin. Hum Genet 112:343-347

Modi D, Berde P, Bhartiya D (2003) Down syndrome: a study of chromosomal mosaicism. Reprod Biomed Online 6:499-503

Schinzel A (2001) Catalogue of unbalanced chromosome aberrations in man, 2nd edn. de Gruyter, Berlin

Schinzel A, Binkert F, Lillington DM, Sands M, Stocks RJ, Lindenbaum RH, Mattews H, Sheridan H (1991) Interstitial deletion of the long arm of chromosome 18, del(18) (q12.2q21.1): a report of three cases of an autosomal deletion with a mild phenotype. J Med Genet 28:352-355

Stankiewicz P, Brózek I, Hélias-Rodzewicz Z, Wiezba J, Pilch J, Bocian E, Balcerska A, Woźniak A, Kardaś I, Wirth J, Mazurczak T, Limon J (2001) Clinical and molecular- cytogenetic studies in seven patients with ring chromosome 18 . Am J Med Genet 101:226-239

Stewart H, Smith PT, Gaunt L, Moore L, Tarpey P, Andrew S, Dady I, Rifkin R, Clayton-Smith J (2001) De novo deletion of chromosome $18 \mathrm{q}$ in a baby with harlequin ichthyosis. Am J Med Genet 102:342-345

Sturm K, Knake S, Schomburg U, Wakat JP, Hamer HM, Fritz B, Oertel WH, Rosenow F (2000) Autonomic seizures versus syncope in 18q- deletion syndrome: a case report. Epilepsia 41:1039-1043

Wertelecki W, Gerald PS (1971) Clinical and chromosomal studies of the $18 \mathrm{q}$ syndrome. J Pediatr 78:44-52

Wyandt HE, Kasprzak R, Lamb A, Willson K, Wilson WG, Kelly TE (1982) Human chromosome 2 rod/ring mosaicism: probable origin by prezygotic breakage and intrachromosomal exchange. Cytogenet Cell Genet 33:222-231

Yardin C, Esclaire F, Terro F, Baclet MC, Barthe D, Laroche C (2001) First familial case of ring chromosome 18 and monosomy 18 mosaicism. Am J Med Genet 104:257-259

Zahed L, Oreibi G, Azar C, Salti I (2004) Ring chromosome 18q and jumping translocation $18 \mathrm{p}$ in an adult male with hypergonadotrophic hypogonadism. Am J Med Genet A 129:25-28

Zannolli R, Pierligi M, Pucci L, Lagrasta N, Gasparre O, Matera MR, Di Bartolo RM, Mazzei MA, Sacco P, Miracco C, de Santi MM, Aitiani P, Cavani S, Pellegrini L, Fimiani M, Alessandrini C, Galluzzi P, Livi W, Gonnelli S, Terrosi-Vagnoli P, Zappella M, Morgese G (2003) 18q-syndrome and ectodermal dysplasia syndrome: description of a child and his family. Am J Med Genet A 116:192-199 